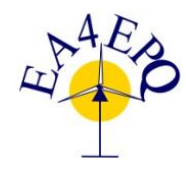

International Conference on Renewable Energies and Power Quality (ICREPQ’13)

Bilbao (Spain), 20 ${ }^{\text {th }}$ to $22^{\text {th }}$ March, 2013

Renemable Eenergy, and Pourer Qualiily, Yournal (RE\&PQJ)

ISSN 2172-038 X, No.11, March 2013

\title{
Power Quality of Supply Characterization in the Portuguese Electricity Transmission Grid
}

\author{
L. Campos Pinto ${ }^{1}$ and A. Tavares ${ }^{1}$ \\ ${ }^{1}$ Management Support Department of the Operation and Maintenance Direction \\ REN - Rede Eléctrica Nacional, S.A. \\ Rua Cidade de Goa, 4 - Sacavém, 2685-039 Sacavém (Portugal) \\ Phone/Fax number: +351210011 000/+351210011825, e-mail: campospinto@ren.pt, alexandra.tavares@ren.pt
}

\begin{abstract}
REN - Rede Eléctrica Nacional S.A., as the concessionaire of the Portuguese National Electricity Transmission Grid (RNT), has an important role in electrical energy quality to the final customer. Continuity of supply general/individual indicators and parameters are defined in accordance to the regulatory legislation stated in the Portuguese Quality of Service Regulation (RQS). Voltage quality assessment is done by REN and is based on a monitoring plan that includes voltage characteristics measurement at selected delivery and internal points.

A study was conducted in order to characterize all the bus bars that were monitored between 2010 and 2011. It was used a simple methodology based on labeling the power quality. On this paper, it will be shown this methodology and the results obtained in characterizing the delivery points of the Portuguese Electricity Transmission Grid (RNT) for the period 2010-2011, as well as other REN quality of supply results in the last years.
\end{abstract}

\section{Key words}

Continuity and quality of supply, flicker, frequency, voltage dips, harmonic distortion, rms voltage.

\section{Introduction}

REN - Rede Eléctrica Nacional S.A. (REN) holds the concession to operate the National Electricity Transmission Grid (RNT). It provides a public utility service in mainland Portugal, as the Transmission System Operator (TSO). It holds as main functions: the management of technical aspects of the National Electricity System (SEN); the transmission of electricity; the management of the interconnections with neighboring TSO; planning, design, construction, operation and maintenance of the RNT; the identification of needs of new power production centers; the study of potential sites for new generation centers; and the global management of the Electricity System of the Public Service (SEP) [1]. REN, as the concessionaire of RNT, has an important role in the electrical energy quality to the final customer.

Voltage quality assessment is done by REN and is based on a monitoring plan that includes voltage characteristics measurement at selected delivery and internal points, such as: harmonic distortion, flicker, voltage unbalance, rms voltage, frequency and voltage dips.

A study was conducted in order to characterize all the bus bars that were monitored between 2010 and 2011. A simple methodology was used based on labeling the power quality. This methodology is similar to the classification that is already in use to define levels of energy efficiency of household appliances. Using this method, it is possible to: aggregate large amounts of measured data into a single indicator; quickly identify areas of RNT best and worst performance for each voltage level; communicate with customers providing simple and understandable information; obtain guidance for future revisions of the Portuguese Quality of Service Regulation (RQS) and for the establishment of power quality contracts with customers.

\section{General Information}

\section{A. Portuguese Electricity Transmission Grid}

By the end of 2012, the transmission lines total length was $8525 \mathrm{~km}$ (81.4 km of underground cables), with $2333 \mathrm{~km}$ of $400 \mathrm{kV}, 3513 \mathrm{~km}$ of $220 \mathrm{kV}$ and $2679 \mathrm{~km}$ of $150 \mathrm{kV}$.

The transmission grid had 64 substations, 13 switching stations, 187 power transformers and autotransformers and 1296 bays, with a total installed capacity of 33765 MVA. 


\section{B. Supply Characterization}

The forecast for total consumption in 2012 is approximately 49 TWh. RNT had 79 delivery points: EHV - extremely high voltage grid $(220 \mathrm{kV}$ and $150 \mathrm{kV})$ $-20 ; \mathrm{HV}-$ high voltage grid $(60 \mathrm{kV})-59$.

\section{Grid Evolution}

In the last six years, the RNT registered a considerable evolution. From 2007 to 2012, the number of substations and switching stations rose by $22 \%$. The number of power transformers and transmission lines also registered a significant increase, with $28 \%$ for power transformers and $15 \%$ for transmission lines total length.

\section{Quality of Supply}

The quality of supply global level depends on the number of incidents that affect the transmission grid, having in account the correlation with climatic conditions.

Despite the significant increase on the principal RNT elements (transmission lines and substations) in the same period (2007-2012) the incidents number had a significant decrease of $22.8 \%$ (Fig. 1 ).

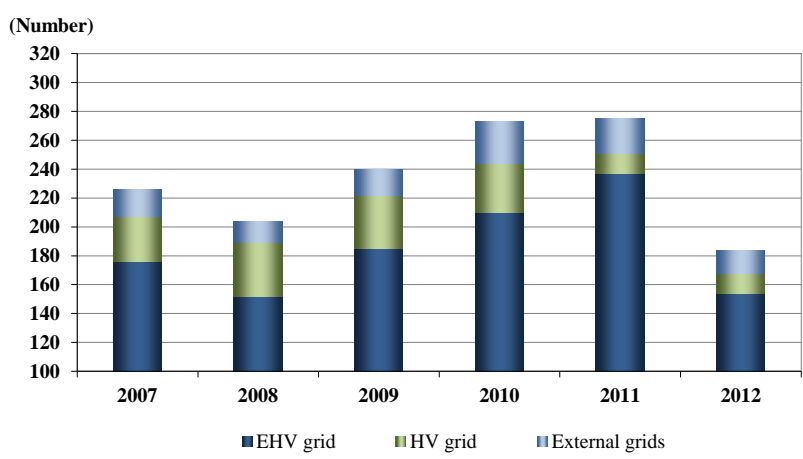

Fig. 1. Incidents number

Between 2007 and 2012, approximately 80-85\% of incidents had origin in overhead lines. The principal causes were: birds (white storks), lightning, forest fires and industrial and saline pollution, in association with fog and mist.

\section{A. Continuity of Supply}

The continuity of supply is the grid permanent capacity to deliver electricity to all customers. When this capacity is not guaranteed, it means that a supply interruption takes place. In some situations, a load shedding can occur. The last significant one was on November 4th, 2006, following a huge disturbance on the European interconnections, originated in Germany.

The continuity of supply indicators and parameters are defined in accordance to the regulatory legislation stated in the Quality of Service Regulation (RQS) [2]. The general indicators are related with the global performance of the transmission grid. The annual determination of these indicators and parameters allows verifying their evolution and to take the necessary corrective measures in a perspective of power quality improvement. The general indicators are the following: Energy Not Supplied (ENS), Average Interruption Time (AIT), System Average Interruption Frequency Index (SAIFI), System Average
Interruption Duration Index (SAIDI) and System Average Restoration Time Index (SARI). The individual indicators, related with the performance of the transmission grid in each delivery point, are: Interruption Duration (ID) and Interruption Frequency (IF). If the parameters for individual indicators are not respected, the company has the obligation to pay compensation to the clients.

For continuity of supply general and individual standards verification only the interruptions with more than 3 minutes are considered and are excluded all interruptions caused by fortuitous reasons or "force majeure", public interest reasons, service reasons, security reasons, circumstances attributable to customers and agreements with customers.

1) Software application - GestInc. To evaluate and quantify the continuity of supply indicators and parameters in the transmission grid delivery points, REN developed custom-made application software for supply reliability management (GestInc). GestInc is a software application, developed inhouse, which purpose is to collect and organize incidents and interruptions data, as well as to perform the automatic calculation for quality indicators under energy regulation. Information is as follows: RNT incidents and their related causes; RNT interruptions number and respective duration, energy not supplied derived from interruptions; RNT continuity of supply indicators in compliance with RQS. GestInc records are filled based on the data gathering from the following main data sources:

- SCADA (Supervisory, Control and Data Acquisition) information;

- Recording sequential data provided from substations data loggers;

- Information from other utilities, namely from EDP Distribution.

Fig. 2 shows the representative data flow from an incident record till continuity of supply indicators.

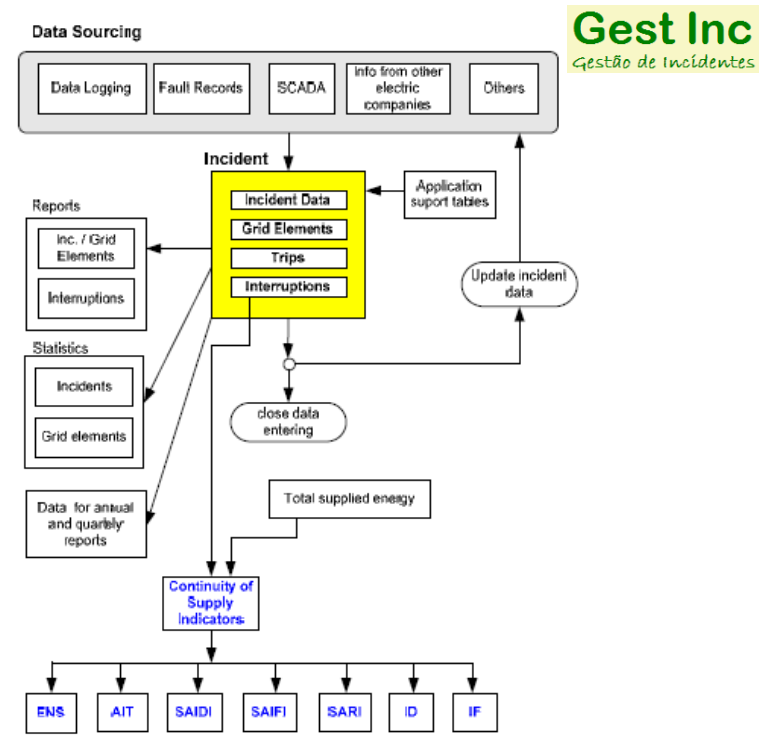

Fig. 2. Data flow of indicators calculation 
2) Continuity of supply indicators - results. For REN, 2012 will be remembered as an historical year regarding Quality of Service because, for the first time, there were no supply interruptions above 3 minutes, achieving a sustained improvement on RNT performance. Concerning this fact, in 2012 the AIT was the best result ever. On the same way, the other indicators (ENF, SAIFI, SAIDI and SARI) reached the best results.

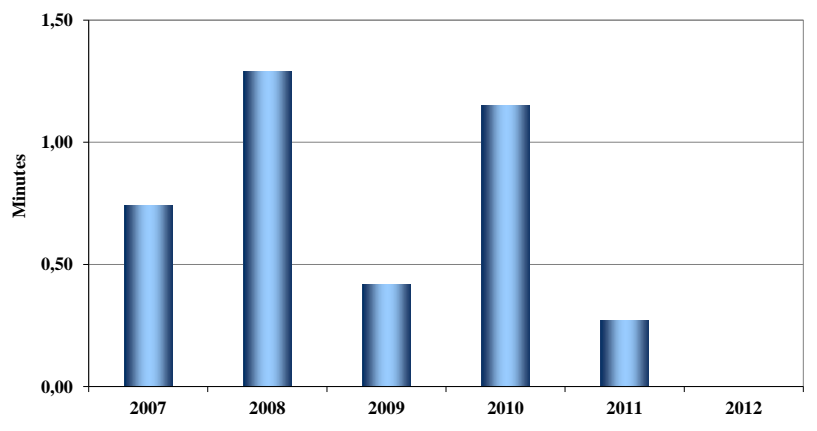

Fig. 3. Average Interruption Time (AIT) evolution

Also the Grid Vulnerability indicator reached an excellent value in $2012(2.72 \%)$. This indicator measures the grid's capacity of not interrupting the energy supplied to customers after an incident, whatever the incidents origin (this indicator considers also "force majeure" incidents, like exceptional winds, floods, forest fires, direct lightning strokes, earthquakes, strikes, public disorder, sabotage, wrongdoing or third party intervention). This indicator is calculated through the ratio between the number of supply interruptions and the number of incidents.

The excellent value reached in 2012 is a consequence of the way the grid is planned, as well as the operation and maintenance measures. The "meshed" grid characteristic with adequate maintenance measures and policies leads to a minimization of the incidents consequences that affect customers.

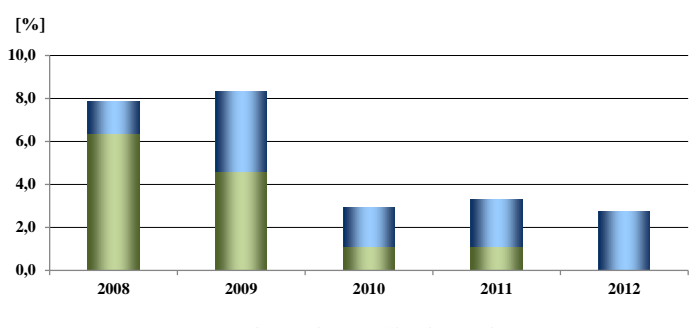

घLong interruptions घShort interruptions

Fig. 4. Grid vulnerability evolution

3) Availability. The availability should be the main characteristic of a transmission grid, as observed by users (customers and producers). In 2009, the Portuguese regulator (ERSE) introduced a new regulatory incentive to increase the availability of the elements of the transmission grid. The objective is to promote the reliability as a key factor on the quality of supply provided and promote an efficient management rule, in line with EU best practices.

The Combined Availability Rate (Tcd) is calculated every month, through the following formula:

$$
T c d=\alpha \times T d_{c l}+(1-\alpha) \times T d_{t p}
$$

where, $\alpha=0.75, T d_{c l}$ is the rate of availability for line circuits (overhead lines and cables) and $T d_{t p}$ is the rate of availability for power transformers.

The target was set at $97.5 \%$. If the Tcd is lower than that target the company has to pay a penalty. On the other hand, if the company achieves a Tcd value higher than $97.5 \%$, then it has the right to receive an incentive.

On Fig.5 and Fig.6 is possible to see the incentive mechanism and the Tcd values since 2008. For the years before 2009, estimation was made (since the incentive mechanism begins only in 2009). In 2012, Tcd reached a new historic maximum $(98.49 \%)$.

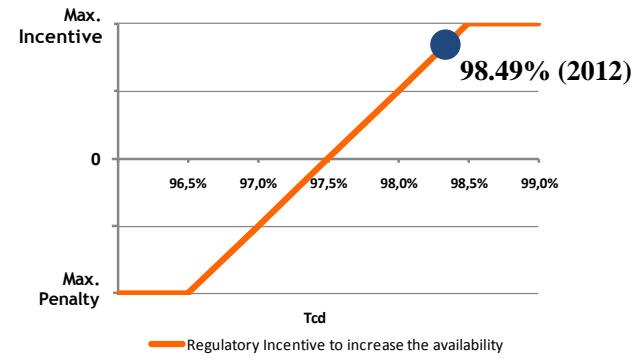

Fig. 5. Regulatory incentive to increase the availability

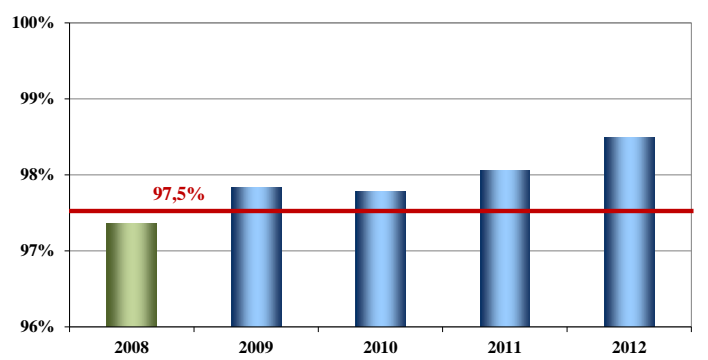

Fig. 6. Combined Availability Rate evolution and target (97.5\%)

\section{B. Voltage Quality}

The voltage waveform quality is affected by some types of disturbances, such as:

- Continuous disturbances that affect the voltage waveform nominal characteristics: frequency variations, slow voltage variation, fast voltage variation (flicker), unbalance, harmonics. These phenomena are mainly caused by grid installations that have non-linear loads or significant load variations; 
- Momentary disturbances, in addition to a singular event, that results on voltage waveform nominal significant characteristics variations: voltage dips and temporary or transient over voltages. This situation occurs in addition to faults in elements of the grid or external factors (environmental and atmospheric events, third party actions, etc.).

REN has implemented a monitoring system to manage the voltage quality, which can be seen below these lines.

1) Monitoring system. The system database records and parameters allow obtaining graphics, reports and correlation between measurements for analysis in the RNT disturbances propagation. The Central Monitoring System (CMS) communicates with Acquisition Remote Units (ARUs), the RENs telecommunications network. The CMS and ARUs synchronization time is obtained by global position system (GPS), to perform the dating and correlation of events with high precision. The voltage quality CMS application (Quality Integrated System - QIS) has important features such as exploration, treatment of the data records, expansion capability, outside communication, organization of information access (menus) and presentation of results (graphics and reports).

2) Monitoring parameters. ARU, based on the sampling of primary electric measures (threephase voltage) and on its chronological records, allows CMS to quantify the various voltage quality parameters mentioned in RQS, related with the HV (60 kV) and EHV (400, 220 and 150 $\mathrm{kV})$. ARU has the capacity to monitor the following parameters defined in EN50160 norm [3]: voltage magnitude (rms) (\% of variation), frequency (limits and \% of variation), flicker severity (Pst and Plt), harmonics spectrum and total distortion $(\%)$, voltage unbalance (\% of variation on the sequence of phases), voltage dips and temporary or transient overvoltage.

3) Acquisition Remote Units - General specifications and localization. The ARUs characteristics are: 3 voltages and 3 currents or 6 voltages, as inputs; 16 bits A/D converter; sampling rating of $25.6 \mathrm{kHz}$; and precision class A. There are 26 permanent remote units (fixed equipment) and 12 periodic remote units (mobile equipment).

4) Central Monitoring System (CMS). CMS works with two servers to process the voltage quality in a "hot standby" operation under Client/Server architecture allowing the access to some competing users. CMS runs on SQL Server relational database on top of Windows Server operating system. The software installed in each server (QIS CMS) has the capability to carry through "polling" and to parameterize the ARUs, to organize all the installations databases, to execute and show the measures in graphics and tables, as well as to edit the conformity reports. An occurrence takes place when the threshold for a given parameter is surpassed and originates a record in the database. That threshold is usually defined by a norm (i.e. EN50160).

An occurrence is characterized as follows by the remote unit name, date and hour of the occurrence, type of occurrence (dips, harmonics, etc.), phase where it occurred, total duration and magnitude.

The waveform is recorded by Informa PMD-A for dips and voltage variations. All the other parameters are recorded in periods of time from 200 milliseconds up to 24 hours. The module of statistics for the remote instruments processes showed electric values each 20 milliseconds (200 milliseconds at Qwave Power), getting the minimum and maximum values as well as average and standard deviation. These four variables are consolidated in statistic sets of 1 hour, 1 day and 1 week.

European norm EN50160 defines the voltage quality delivered in a public grid. Remote instruments automatically verify the conformity of the norm according to the parameters. The conformity reports are generated automatically at the end of each measure plan, usually 1 week.

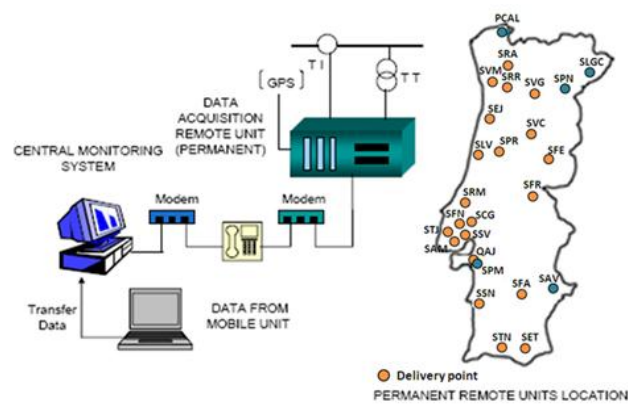

Fig. 7. Voltage quality monitoring system and remote unit localization

5) Monitoring Plan of the voltage quality. Following the RQS, REN is obliged to monitor all delivery points over a period of two years. The monitoring plan allows verifying the accomplishment of technical standards and is constituted by a set of measurements to carry through RNT and delivery points. These measurements are taken at substation bus bars using fixed equipment (fixed ARU) installed in the transmission grid and mobile equipment (mobile ARU) to record possible disturbances.

The monitoring plan is designed having as purposes: to cover all the regions in the country and the different voltage levels in RNT; to coordinate the measurements on RNT strategic points (including interconnections with Spain) with the distribution operator measurements in order to determine the disturbances origin; and the identification of new actions concerning the 
previous results. REN sends to the regulator quarterly reports, files with quality of supply indicators and parameters and an annual report, according to RQS.

6) Voltage Quality Results. In general, the disturbances average values are relatively low and the (indicative) regulatory limits are fulfilled in more or less $92 \%$ of the delivery points. The majority of the voltage dips had durations lower than 250 milliseconds and dip amplitude of $30 \%$ of the rms voltage value. These results are globally acceptable.

\section{Labelling Power Quality}

Many customers are not familiar with power quality concepts. That is why it is so important to kept information very simple and understandable. In addition to this, DNOs (Distribution Network Operators) in the Netherlands have initiated an easy classification system based on labeling the power quality [4], [5]. This system is already in use to classify the energy efficiency of household appliances. On Fig.8 it is possible to see the classification levels.

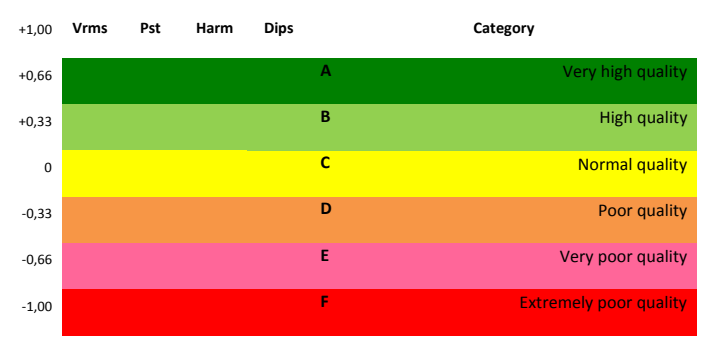

Fig. 8. Classification of power quality characteristics

First, it is necessary to normalize all power quality characteristics level, using the following formula:

$$
r_{(c, b, p)}=1-\frac{m_{(c, b, p)}}{l_{(c)}}
$$

where, $r_{(c, b, p)}$ is the normalized power quality characteristic $c$, on bus bar $b$, for phase $p ; m_{(c, b, p)}$ is the actual level of characteristic $c$, on bus bar $b$, for phase $p$; and $l_{(c)}$ is the compatibility level of characteristic $c$.

The normalized value will be: $1(m=0)$ if there is no disturbance; 0 if the disturbance level is equal to the applicable standard; negative if the disturbance level exceeds the specified limit.

However, the previous equation is not applicable to voltage dips on the Portuguese reality. In Portugal there are no standard limits for voltage dips, that is why it is not possible to use the formula above. Nevertheless, a comparison analysis of all the bus bars was made. The following methodology was used [6]:

$1^{\circ}$ It was attributed a weighting factor for each voltage dip based on the amplitude and duration (severity) of the dip.

$$
S_{e}=\frac{1-U}{1-U_{r e f}(d)}
$$

where, $U$ is the voltage amplitude (\% of nominal voltage); $d$ is the duration (severity); and $U_{r e f}(d)$ is the voltage amplitude reference for duration $d$. The reference curve recommended for this method is the SEMI (Semiconductor Equipment and Materials International Group) curve, which is a variant of the ITI curve;

$2^{\circ}$ The following step is the ratio of the sum of severities of all dips by the considered monitoring periods, for each bus bar. This step leads to an average value per period;

$3^{\circ}$ For the best and the worst bus bars ( $2^{\text {nd }}$ step) we assume that the normalized value is +1 and -1 ;

$4^{\text {o }}$ Having in account the previous step and the first equation, the reference value for the grid is achieved by the average of the best and the worst values;

$5^{\circ}$ Using the equation (2), where $m_{(c, b, p)}$ is the individual result for each bus bar ( $2^{\text {nd }}$ step) and $l_{(c)}$ the reference value $\left(4^{\text {th }}\right.$ step), we obtain the classification $r_{(c, b, p)}$ for each bus bar.

However, it is important to clarify that this classification only allows evaluating the bus bars relative performance. It is not possible to compare these results with other grids.

1) Results. The focus of analysis was the period 2010-2011. REN monitoring annual plans included measurements of:

- Permanent remote units (26 installations) with voltage levels characteristics measurements during 52 weeks per year;

- Periodic remote units, installed in a way that allows taking a global view of the RNT voltage quality (in 4 weeks periods).

The results obtained were of two types: continuous phenomena characteristics and shortduration events (voltage dips). The continuous phenomena data are made by the weekly $95^{\text {th }}$ percentile (of all weeks and bus bars that were monitored). There were considered two levels of $95^{\text {th }}$ percentile: the maximum value and the median value. This methodology allows reaching two different results: the less favorable week and the representative week classifications, over the year of measurements.

For voltage dips it was used the method that was previously mentioned. It was only considered bus bars with permanent remote units. Measuring periods lower than one year does not allow reaching consistent values because of the dips seasonality. This is why periodic remote unit measurements were not considered.

On the Fig. 9, there are four Portugal maps, one for each voltage level $(60,150,220$ and $400 \mathrm{kV})$. It is represented the global evaluation of RNT 
installations, for continuous phenomena. This evaluation is based on the worst characteristic (the worst value of the representative week) for each measured point. These characteristics are only the ones that have normative limits. Voltage unbalance and frequency were not considered because deviations values were not significant (weighted against the standard limits). On the Fig. 10 it is possible to see the global value for voltage dips (for all bus bars).

\section{Conclusions}

In the last years, REN achieved an excellent performance regarding quality of supply as shown by the relevant indicators. As many customers are not familiar with power quality concepts, it is important to kept information very simple and understandable. In addition to this, an easy classification system based on labeling the power quality was used in order to classify the voltage quality on delivery points. This system is already in use to classify the energy efficiency of household appliances.

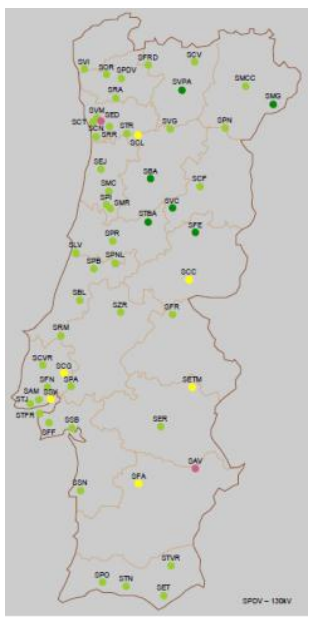

$60 \mathrm{kV}$ bus bars

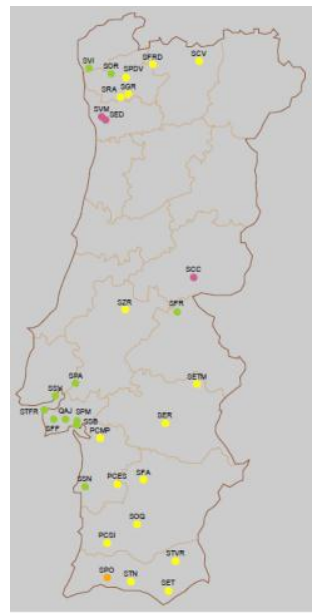

$150 \mathrm{kV}$ bus bars

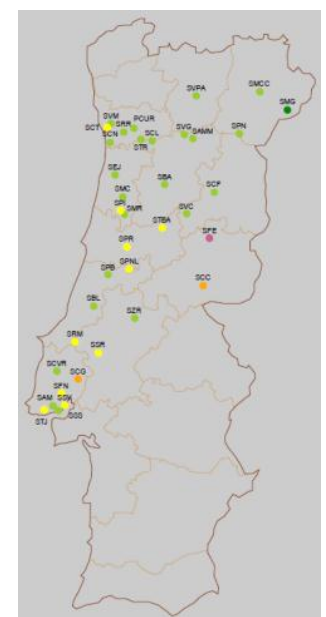

$220 \mathrm{kV}$ bus bars

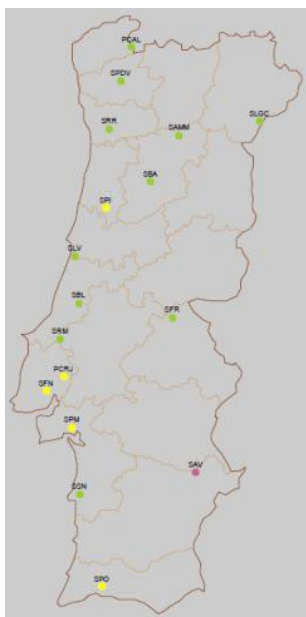

$400 \mathrm{kV}$ bus bars

Fig. 9. Global voltage quality classification per bus bar (continuous phenomena)

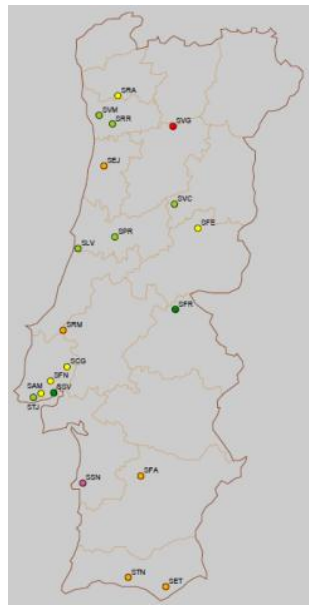

$60 \mathrm{kV}$ bus bars

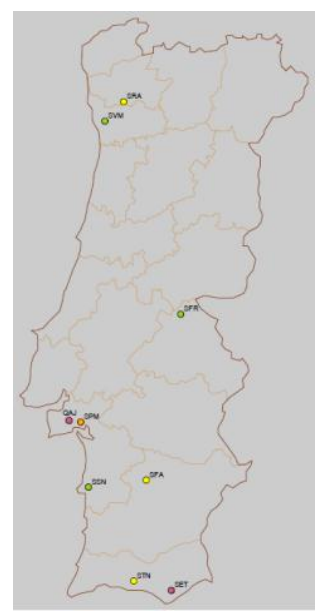

$150 \mathrm{kV}$ bus bars

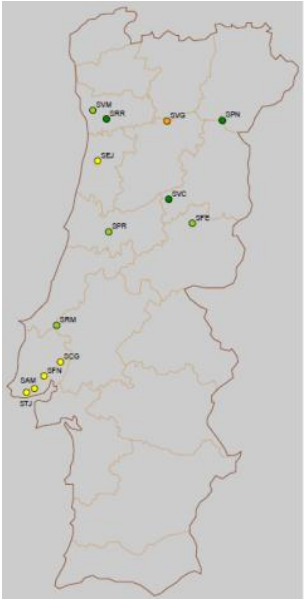

$220 \mathrm{kV}$ bus bars

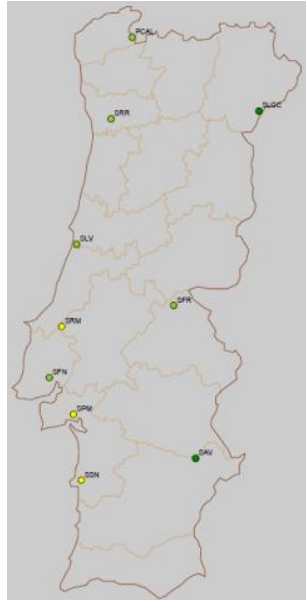

$400 \mathrm{kV}$ bus bars

Fig. 10. Global voltage quality classification (short-duration events) 


\section{References}

[1] A. Meneses and L. Campos Pinto, "Quality of Supply at the Portuguese Electricity Transmission Grid", IEEE EPQU 2011.

[2] ERSE-Entidade Reguladora dos Serviços Energéticos, "Regulamento da Qualidade de Serviço", 2006.

[3] European Norm EN50160 Voltage characteristics of electricity supplied by public electricity networks, 2010.

[4] J.F.G. Cobben, and J.F.L. van Casteren, "Classification Methodologies for Power Quality", Electrical Power Quality and Utilization Magazine Vol.II, No.1, 2006.

[5] W.T.J. Hulshorst, E.L.M. Smeets, and J.A. Wolse, "Premium Power Quality Contracts and Labeling", Work package 2 of the Quality of Supply and Regulation Project, KEMA Consulting, 2007.

[6] A. Tavares and L. Campos Pinto, "Power Quality of Supply Characterization in the Portuguese Electricity Transmission Grid", $8^{\text {th }}$ International Conference Electric Power Quality and Supply Reliability, 2012. 